\title{
A Typical Case of Child Abuse: A Case Report
}

\author{
Nepal D', Dhakal A², Banstola D³, Mahaseth C4
}

${ }^{1}$ Dr. Deepeshwara Nepal, MBBS, MD(Paediatrics), WHO Fellow in Neonatology, Senior Medical Officer, Kanti Children Hospital, Kathmandu, ²Dr. Ajaya Kumar Dhakal Paediatrics Resident, IOM, Tribhuvan University Teaching Hospital, ${ }^{3}$ Dr. Banstola Dinesh, Assistant Professor of Physiology, Tribhuvan University Teaching Hospital, ${ }^{4}$ Dr. Chandeshwar Mahaseth Professor of Paediatrics, National Academy of Medical Sciences, Bir Hospital, Kathmandu.

Address for correspondence: Dr. Deepeshwara Nepal, E-mail: dnepal123@hotmail.com

\begin{abstract}
Child abuse is common but still unnoticed, undiagnosed, neglected childhood problem in Nepal. Child abuse has diverse clinical manifestation ranging from minor injury to severe head trauma to simulating severe medical problem. The true incidence of intentional head injury in children remains uncertain in Nepal. We are reporting a case of child abuse with blunt head trauma with intracranial hemorrhage presenting as a loss of consciousness simulating as a diabetic ketoacidosis (DKA)
\end{abstract}

Key words: Children, child abuse, DKA

\section{Introduction}

$(2$ hild abuse is very common pediatric problem worldwide and its incidence is increasing in Nepal and requires a high index of clinical suspicion to make diagnosis. Head injury and its complications of intracranial hemorrhage is one of the main causes of death due to child abuse ${ }^{1}$. As most of cases are often not suspected from history they are often missed in $30 \%$ of cases ${ }^{2}$. Every year, about $4-16 \%$ of children are physically abused and one in ten is neglected or psychologically abused. ${ }^{3}$ Child abuse has iceberg phenomenon, with only tip presents to pediatrician with most of cases hidden in society. The identification of suspected abuse is urgently required not only to treat the current condition, but also to protect the child from a subsequent, perhaps more serious, injury. An abused child may have as much as a 50 percent chance of incurring further abuse and a 10 percent chance of dying if abuse is not detected at the initial presentation ${ }^{4,5,6}$. A delay in seeking medical care; in 40 percent of cases of abuse, parents delay seeking care until the day after the child's injury occurs, and another 30 percent delay seeking care until one to four days after the injury?

\section{The Case}

A six year girl was brought to pediatric emergency department of Kanti Children's Hospital with history of loss of consciousness for one and half hour. There was no history of fever, ear discharge, and abnormal movement of any part of the body, up rolling of eyes, frothing from mouth, incontinence of urine or stool. There was a history of accidental injury at the left side of the cheek due to banging against the door six days prior to this episode but without any history of loss of consciousness at that time. There were two similar history of loss of consciousness (LOC) six months back, at fifteen days interval. Each episode lasted for about 34 minutes and the child regained consciousness on her own without any medication. No medical help was taken at that time for LOC.

Past histoty suggested that there was a history of increased appetite without weight gain since three years of age. She also had a history of increased frequecy of urination about 8-10 times during daytime and 6-7 times at night for the past one year. She had excessive bleeding after trivial skin injury but no history of gum bleeding or blood in urine and stool. There was easy bruising but the 
reliability regarding bruises were contradictory amongst both the father and mother when asked separately (father said that they were present before and occurred during playing, while the mother stated that they were present after coming to the hospital only).

She was a product of a non-consanguineous marriage between a 28 year old father who is a taxi driver by profession in Kathmandu and a 22 year old housewife mother. She was born at home, full term, normal delivary, with an unknown birth weight. Antenatal, natal and post natal periods were uneventful; there was no excessive bleeding from the umbilical stump. She was living with her step mother as her own mother was out of the country since the last three years. There was no history suggestive of bleeding disorder in family. She has an eight month old younger brother who did not have problems similer to hers. She was immunized as per EPI Schedule and there was no history of developmental delay.

On physical examination she was ill looking with poor GCS (7/15) and stable vitals. CRT was <2sec, SPO2: $100 \%$ with $\mathrm{O}_{2}$ at 2liters per minute via nasal prongs. There was neither kussmaul breathing nor any signs of dehydration. There was no pallor, lymphadenopathy, cyanosis, clubbing and edema. There were multiple bruises of different ages all over the body including injury marks on the labia majora with bruising. There was bowing of the left upper limb and right lower limb. Her weight for age was $50 \%$ of expected (Grade: IV-according to IAP classification). CNS examination revealed poor GCS (7/15), bilatreally unequal and non reacting pupils, both the planters were up going and there were no signs of meningeal irritation. Muscle tone was normal but the power was decreased (2/5), Deep Tendon Jerks in the upper limbs were normal but exaggerated in the lower limbs. Other systems were essentially normal.

Investigations showed that the blood glucose was $226 \mathrm{mg} \%$ and urine ketones were positive. But after 12 hours the blood sugar level was normal and ketones were also negative. Renal function tests and coagulation profile were both normal. Skeletal survey showed healing fractures of multiple bones. Neuroimaging could not be done. Based on the history which was unreliable, with the child having bruises all over the body including the genital region, multiple fractures, transiently high blood sugar and a normal coagulation profile, a diagnosis of child abuse was suspected.

Police were informed from the very beginning and legal procedures were started. In spite of close monitoring, ventilator care and extensive supportive care in the PICU, the child's condition remained poor. She died on the eighth day of admission. Her body was sent for postmortem. Post mortem findings on external examination was similar to our findings. Howerever on internal examination there was even a subdural hematoma at the occipital region which was suggestive of blunt injury to the head. Child abuse was confirmed and necessary actions taken against the parents.

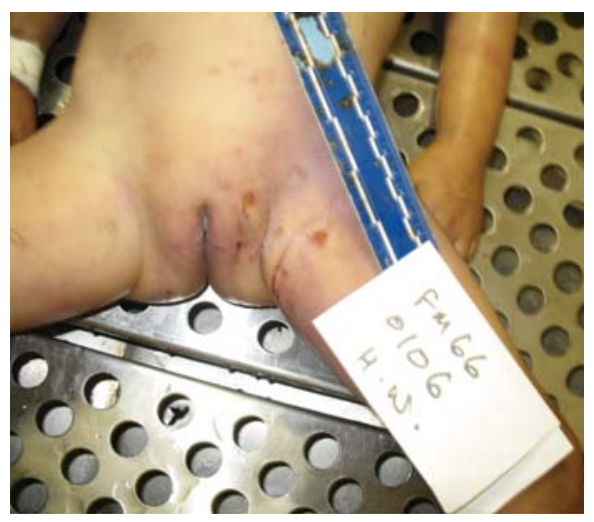

Fig. 1: Showing Multiple Bruises of Different Sizes on Lower Abdomen and Perennial Region.

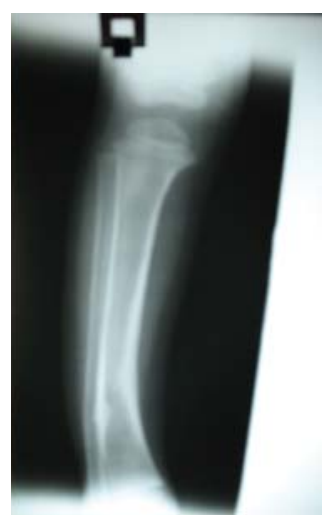

Fig. 2: X-Ray of Right Leg (Callus formation suggestive of old fracture).

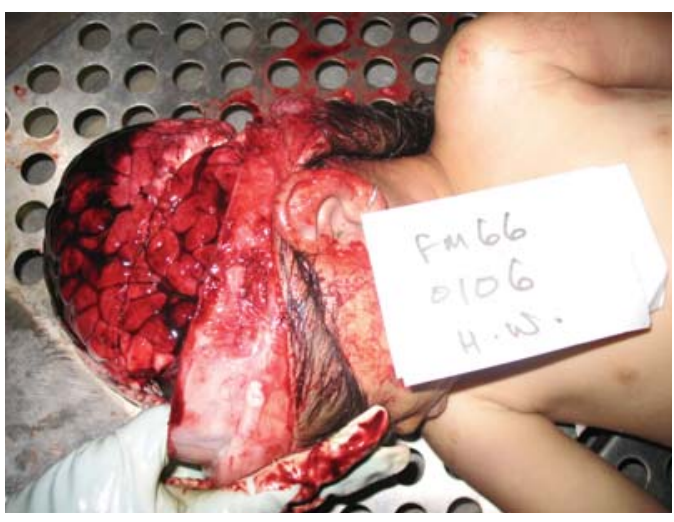

Fig. 3: Showing the Subdural Haematoma at Left Perieto-Occipital region. 


\section{Discussion}

This case highlights the fact that child abuse has to be considered in the differential diagnosis of many childhood disease conditions like bleeding disorder, coagulopathy and head injury. Many a times we fail to recognize such conditions thus neglecting child abuse and failing our medical duties towards the health of children. Child maltreatment is defined as intentional harm or threat of harm to a child by a person who is acting as the role of caretaker ${ }^{8}$. Child abuse can take many forms, such as physical abuse, sexual abuse, emotional abuse and child neglect. Defining a given behavior as abusive and harmful varies both and within cultures as well as overtime. Cupping, coining, spooning, moxibustion etc are culturally acceptable practices ${ }^{9}$. Child abusers are isolated with low self esteem, unemployed, and poor, usually themselves victims of abuse in childhood. Ten percent of such perpetraitors are psychotic or sociopaths. Mentally handicapped children are at a higher risk for the same. The biggest myth is that the dangers come from strangers but in most of the cases the abuser is someone the parents or child knows and is often trusted by parents or family. Separating head injury from accidental cause from non accidental causes may be difficult ${ }^{10}$. Children with noninflicted traumatic brain injury ( $\mathrm{TBI}$ ) were more likely to present to the emergency department as compared to children with inflicted TBI $(44.8 \% \text { vs. } 8.3 \%)^{11}$. Ophthalmic examination of children with suspected abuse is important for prognostic as well as diagnostic purposes. In purpoely inflicted injuries; retinal hemorrhages are likely to be multiple, bilateral, involving the pre-retinal and intra-retinal layers, cover the macula, and extend to the periphery of the retina ${ }^{12}$. The finding of subdural hemorrhages on different sides or of apparently different densities or of generalized edema is strongly suggestive of purposely inflicted $\mathrm{TBI}^{13}$. Factors strongly related to poor outcome are young age, duration of unconsciousness, and low Glasgow coma scale $^{14}$. Clinicians need to be aware of the possibility of child abuse in any case of traumatic head injury without history of antecede.

Eventhough UN Convention articles 49, on the rights of the child came in to force on September 2, 1990, the violations of rights of children has been increasing. 1.5 million girls and 7.5 million boys worldwide were abused sexually in 2002 (UN secretary General Report). Among School going children of Kathmandhu, more than 40 percent children have reported being abused sexually (CWIN-SCNN study 2003).

Every child has a right to health and life free from violence and abuse. Whilst we recognize a child as an individual possessing rights, it is imperative to have laws and procedures that operate in the best interest of the child and that they protect every child from violation of their rights; thereby helping them to become healthy and responsible adults.

Everyday as practising pediatrician we come across cases of child abuse or neglect in various forms but we often fail to recognize some forms of abuses. Even if we do suspect or diagnose it, there seems to be little that we can do to deal with it. It is important that there be empathy and coordination between various agencies that deal with child wellfare. Paediatricians are the first to be in contact with a child in need of protection, so they need to recognise child abuse or neglect and they need to incorporate their knowledge and the skills to address this in their day to day practise.

\section{References}

1. Duhaime AC, Christian CW, Rorke LR, Zimmerman RA. Nonaccidental head trauma in infants the "Shaken baby syndrome". N Engl J Med 1998; 338: 1822-9.

2. Jenny C, Hymel KP, Ritzen A, Reinert SE, Hay TC. Analysis of missed cases of abusive head trauma. JAMA 1999; 281: 621-6.

3. Gilbert, R, Widom, CS, Browne, K, et al. Burden and consequences of child maltreatment in highincome countries. Lancet 2009; 373:9657 1-94.

4. Saade, DN, Simon, HK, Greenwald, M. Abused children. Missed opportunities for recognition in the ED. Acad Emerg Med 2002; 9:524.

5. Rosenberg, LA, Wissow, LS. Effects of maltreatment on the child. In: Child Advocacy for the Clinician: An Approach to Child Abuse and Neglect, Williams and Wilkins, Baltimore 1990. p.12.

6. Loder RT, Bookout C. Fracture patterns in battered children. J Orthop Trauma 1991; 5:428.

7. Wagner, GN. Crime scene investigation in childabuse cases. Am J Forensic Med Pathol 1986; $87: 94$.

8. Wissow, LS. Reporting suspected child maltreatment. In: Child Advocacy for the Clinician: An Approach to Child Abuse and Neglect, Wissow, LS (Ed), Williams and Wilkins, Baltimore 1990. p.209.

9. Stewart, GM, Rosenberg, NM. Conditions mistaken for child abuse: part II. Pediatr Emerg Care 1996; 12:217. 
10. Hettler J, Greenes D. Can the initial history predict whether a child with head injury has been abused? Pediatr 2003; 111: issue 3: 602-7.

11. Keenan HT, Runyan DK, Marshall SW, Nocera MA, Merten DF. A population-based comparision of clinical and outcome characteristics of young children with serious inflicted and non-inflicted traumatic brain injury. Pediatrics 2004; 114: 633- 9.

12. Bechtel K, Stoessel K, Leventhal JM, Ogle E, Teague B, Lavietes $S$, et al. Characteristics that distinguish accidental from abusive injury in hospitalized young children with head trauma. Pediatr 2004; 114: 165- 8.

13. Datta S, Stoodley N, Jayawant S, Renowden S, Kemp A. Neuroradiology aspects of subdural haemorrhages. Arch Dis Child 2005; 90: 947-1.

14. Prasad MR, Ewings- Cobbs L, Swank PR. Predictors of outcome following traumatic brain injury in young children. Pediatr Neurosurg 2002; 36: $64-4$ 